\title{
Arrays of copper nanowire electrodes: Preparation, characterization and application as nitrate sensor
}

\author{
A.M. Stortini ${ }^{a}$, L.M. Moretto ${ }^{a}$, A. Mardegan ${ }^{b}$, M. Ongaro ${ }^{a}$, P. Ugo ${ }^{a}, *$ \\ a Department of Molecular Sciences and Nanosystems, University Ca' Foscari of Venice, Dorsoduro 2137, 30123, Venice, Italy \\ ${ }^{\mathrm{b}}$ Veneto Nanotech, via delle Industrie 5, Marghera, 30175, Venice, Italy
}

\section{A R T I C L E I N F O}

\section{Article history:}

Received 31 July 2014

Received in revised form

25 September 2014

Accepted 29 September 2014

Available online 6 October 2014

\section{Keywords:}

Nanoelectrode

Array

Copper

Nanowire

Voltammetric sensor

Nitrate

\begin{abstract}
A B S T R A C T
Ensembles of copper nanowire electrodes (CuWNEEs) are prepared via electrodeposition in track-etched polycarbonate membranes. Three different preparation methods are compared showing that the better results in terms of sensor durability and reproducibility are achieved by pre-sputtering a thin gold film on the templating membrane and attaching it to a supporting electrode by exploiting the adhesion property and ionic conductivity of a thin Nafion interlayer. SEM-EDS analyses together with double layer charging currents measurements indicate that these arrays are formed by copper nanowires with $400 \mathrm{~nm}$ diameter, $10 \mu \mathrm{m}$ length distributed with a spatial density of $1 \times 10^{8}$ nanowires $/ \mathrm{cm}^{2}$. The voltammetric reduction of nitrate at CuWNEEs is characterized by a well-resolved cathodic peak at approximately $-0.680 \mathrm{~V}$ vs $\mathrm{Ag} / \mathrm{AgCl}$, whose current scales linearly with the nitrate concentration in the $10-400 \mu \mathrm{M}$ range. The limit of detection (LOD) achieved by simple linear sweep voltammetry is in the 1.7-3.0 $\mu \mathrm{M}$ range, depending on the CuWNEE preparation method, such LOD values being among the lowest reported up to now in the literature. The possibility to use CuWNEEs in chloride and nitrite containing water samples is demonstrated.
\end{abstract}

@ 2014 Elsevier B.V. All rights reserved.

\section{INTRODUCTION}

In the last years the properties and advantageous characteristics of array of nanoelectrodes to be employed as sensitive voltammetric sensors have been demonstrated [1-7]. The largest part of these studies was developed using ensembles of gold nanoelectrodes (NEEs) prepared via electroless deposition. From an analytical viewpoint, metals different from Au were seldom studied, with few exceptions such as for instance, Bi modified NEEs [8], applied for ultratrace lead (II) analyses. Recently, a simple and effective electrodeposition method for obtaining copper NEEs was proposed [9], where copper is an interesting electrode material suitable for the detection of analytes electroactive at negative potential values. Moreover copper presents high electrocatalytic activity for nitrate reduction in comparison, for instance, with gold [10].

Major anthropogenic sources of nitrate in food and environment are associated to its use as inorganic fertilizer, food preservative, and as reactant for the production of explosives or glass, and other chemicals. In surface waters, nitrate level is normally low (tens of

\footnotetext{
* Corresponding author.

E-mail address: ugo@unive.it (P. Ugo).
}

$\mathrm{mg} \mathrm{L}^{-1}$ ), but higher levels can be reached by agricultural runoff, refuse dump runoff or contamination with wastes [11]. Toxicity of nitrate to humans is related to the ability of nitrate to oxidize hemoglobin ( $\mathrm{Hb})$ to methemoglobin (metHb), which is unable to transport oxygen in the tissues, this process being responsible for the "blue-baby" syndrome or methemoglobinemia [11]. Moreover, nitrate can be the precursor of nitrite whose carcinogenic effects on the gastrointestinal apparatus (nitrite is a precursor of endogenous nitrosamines and nitrosamides) or congenital malformation effects are documented [11].

The limit of concentration for nitrate in drinking water indicated by the European Directives (1991/676/EC, 1998/83/EC, 2003/40/EC) and the World Health Organization (WHO) in the guidelines for drinking-water quality, is $50 \mathrm{mg} \mathrm{L}^{-1}$; Italian regulations set this limit to $45 \mathrm{mg} \mathrm{L}^{-1}$ for regular drinking water, which is lowered to $10 \mathrm{mg} \mathrm{L}^{-1}$ for waters to be used for infants nutrition.

A variety of analytical techniques are available for the analysis of nitrate in the environment, including colorimetry after reduction to nitrite, direct UV spectroscopy, ion-exchange chromatography, and potentiometry with ion-selective electrodes [12]. Recently, many studies have been devoted to the development of voltammetric and amperometric methods of analysis with the advantage of furnishing high sensitivity with short response time, using cheap instrumentation and being suitable for direct or on-site analyses, 
even in turbid or colored samples. However, in the case of nitrate analyses, dynamic electrochemical methods must face with the high overpotential which affects the direct electrochemical reduction of $\mathrm{NO}_{3}{ }^{-}$. Different approaches have been proposed to this aim, such as the use of modified electrodes which exploit electrocatalysis by $\mathrm{Yb}(\mathrm{III})$ and $\mathrm{UO}_{2}{ }^{2+}$ [13] or $\mathrm{Co}(\mathrm{III}), \mathrm{Ru}(\mathrm{II}), \mathrm{Zn}(\mathrm{II})$, and $\mathrm{W}$ complexes $[14,15]$, as well as by immobilizing on electrode surfaces suitable reductase enzymes [16-18].

An alternative approach is offered by the use of metal electrodes able to furnish analytically useful signals relevant to nitrate reduction and, among the others, copper is the most widely and successfully used [10,19-24]. In acidic solutions, the electrochemical reduction of nitrate produces $\mathrm{NH}_{3}$ [19]; however, the rate determining step is the reduction of nitrate to nitrite [25] involving $\mathrm{NO}_{3}{ }^{-}$anions adsorbed on the copper surface. Recently, it was demonstrated that the nanostructuration of the copper surface can further improve the electroanalytical performances of copper electrodes, allowing the direct detection of nitrate in the ten micromolar range or even lower [25-27]. This can be due to the presence of a larger number of reactive sites in a nanostructured electrode as well as to a possible influence of the nanostructuration of the surface on the diffusion regime, as demonstrated for other analytical cases where arrays of gold nanowire or carbon nanotube electrodes were employed [28-31]. As far as copper electrodes are concerned, in the previous researches, the nanostructuration of the surface was achieved by deposition of a macroporous copper deposit [25] or by anodic dissolution and subsequent reduction of copper cations [26,27]. Notwithstanding the good results obtained with such approaches, some limits come from the scarce reproducibility in the preparation of the activated surface, particularly when obtained in-situ, and the lack of full control in directing the morphology of the nanostructured surface. In order to obtain arrays of copper electrodes in which the nanostructuration of the sensor surface is highly controlled, in this work we prepare ensemble of copper nanowires (CuWNEEs) by template electrochemical deposition of $\mathrm{Cu}$ into the pores of track-etched polycarbonate membranes $[32,33]$. The CuWNEEs are carefully characterized and applied as sensors for nitrate determination in water samples; to the best of our knowledge, this is the first example of successful application of copper nanowire electrodes as sensors for analytical application.

\section{EXPERIMENTAL}

\subsection{Materials and Chemicals}

All chemicals were of analytical grade and used without further purification. Solutions were prepared with doubly distilled water $\left(18.2 \mathrm{M} \Omega \mathrm{cm}^{-1}\right)$. Cu deposition was performed at room temperature in $\mathrm{CuSO}_{4}\left(100 \mathrm{~g} \mathrm{~L}^{-1} / 0.4 \mathrm{M}\right), 10^{-2} \mathrm{M} \mathrm{H}_{2} \mathrm{SO}_{4}$. Voltammetric measurements were performed in $0.1 \mathrm{M} \mathrm{Na}_{2} \mathrm{SO}_{4}$ supporting electrolyte acidified to $\mathrm{pH} 3.0$ with $\mathrm{H}_{2} \mathrm{SO}_{4}$. Real samples were acidified at $\mathrm{pH} 3$ with $\mathrm{HCl}$ (see Section 3.4). Track-etched polycarbonate (PC) membranes (SPI-pore) with $400 \mathrm{~nm}$ pore diameter, thickness $10 \mu \mathrm{m}$, and pore density $1 \times 10^{8}$ pores $\mathrm{cm}^{-2}$ were used as templates for the electrochemical deposition. Nafion ${ }^{\circledR} 117,5 \% \mathrm{w} / \mathrm{v}$ solution (Sigma-Aldrich) was diluted before use to $0.5 \%$ with methanol. Bottled mineral drinking water was bought at a local supermarket.

\subsection{Instrumentation}

\subsubsection{Electrochemical instrumentation and methods}

Electroanalytical measurements were performed at room temperature $\left(22 \pm 1^{\circ} \mathrm{C}\right)$ under a nitrogen atmosphere, in a conventional single-compartment cell equipped with a platinum wire counter electrode and a $\mathrm{KCl}$ saturated $\mathrm{Ag} / \mathrm{AgCl}$ reference electrode to which all potentials reported are referred here. The working electrodes were a PTFE-shrouded copper disk electrode (CuE) (area $0.071 \mathrm{~cm}^{2}$ ) mirror polished with graded alumina powder (3 and $0.5 \mu \mathrm{m}$ ), or CuWNEEs prepared as described below. Electrochemical measurements were performed with a CHI1000 workstation ( $\mathrm{CH}$ Instruments, USA). Nitrate electroanalyses were performed in $100 \mathrm{mM} \mathrm{Na}_{2} \mathrm{SO}_{4}, 1 \mathrm{mM} \mathrm{H}_{2} \mathrm{SO}_{4}$ (pH 3 ) supporting electrolyte.

\subsubsection{Scanning Electron Microscopy}

Scanning electron microscopy (SEM) and energy dispersive spectroscopy (EDS) analysis were performed using a TM3000 Hitachi tabletop scanning electron microscope coupled with a Xray microanalysis system (SwiftED3000); conditions for recording the EDS spectra were: acquisition time $30.0 \mathrm{~s}$; process time $5 \mathrm{~s}$; accelerating voltage $15 \mathrm{kV}$.

\subsubsection{Ion-chromatography}

Ion chromatography was performed with a Metrohm 761 IC chromatographer equipped with a polyvinyl alcohol column with quaternary ammonium groups (IC Anion Column Phenomenex STAR ION A300). The eluent used was $1.8 \mathrm{mM}$ sodium carbonate $+1.7 \mathrm{mM}$ sodium hydrogen carbonate solution with a conductivity of $14 \mu \mathrm{S} \mathrm{cm}^{-1}$ after chemical suppression.

\subsection{Template Electrochemical Deposition}

Details on the different approaches used to attach the membrane on an underlying Cu-disk electrode ( $3 \mathrm{~mm}$ diameter) are described in Section 3.1. After completing the copper deposition, the PC layer was totally removed by repeatedly washing with $\mathrm{CH}_{2} \mathrm{Cl}_{2}$. When required an hydroalcoholic solution of Nafion was used to glue the PC template onto the underlying $\mathrm{Cu}$ disk electrode. In some tests, a thin layer of gold was pre-sputtered on one face of the PC membrane, when required, using a plasma sputter-coater (mini deposition system BALZERS MED 010) in the following conditions: distance from target $(d=50 \mathrm{~mm})$, current $(i=15 \mu \mathrm{A})$, time of sputtering ( $t=60 \mathrm{~s}$ ), working pressure ( $p=0.05 \mathrm{mbar}$ ), and argon as operating gas. On the basis of preliminary calibrations, the estimated thickness of the sputtered gold layer was $12-15 \mathrm{~nm}$.

\section{RESULTS AND DISCUSSION}

\subsection{Template Copper Electrochemical Deposition}

Three different potentiostatic procedures were used to grow copper nanowires into the pores of track-etched PC membrane, the difference being the procedure by which the membrane is stuck to the $\mathrm{Cu}$-disk working electrode. The first method, named here as method (A), is based on the approach recently proposed by Gambirasi et al. [9], in which the PC membrane is gently forced to adhere onto the $\mathrm{Cu}$ electrode by the pressure furnished by a piece of melamine foam (see Fig. 1A). The counter electrode, which acts also as pseudo-reference, is an L-shaped copper sheet located in front of the working electrode. Note that the melamine foam and the PC membrane are preconditioned, by dipping in the $\mathrm{Cu}^{2+}$ solution for at least $2-3 \mathrm{~h}$, to assure full wetting of the foam before starting the electrochemical deposition. In methods (B) and (C) illustrated (shown in Fig. 1B and $1 \mathrm{C}$, respectively), the PC membrane is attached to the flat $\mathrm{Cu}$-disk electrode by exploiting the adhesion capability of an interlayer of Nafion used as a sort of polielectrolytic glue. In practice, a microvolume $(2.5 \mu \mathrm{L})$ of hydroalcoholic Nafion dispersion is applied on the Cu-disk, then a piece of PC membrane is carefully positioned over the Nafion-wetted copper disk and the solvent is allowed to dry at room conditions. The difference between method (B) and (C) is that, in the latter, the side of the PC membrane which is in contact with the $\mathrm{Cu}$ disk is pre-sputtered with a thin layer of gold. 

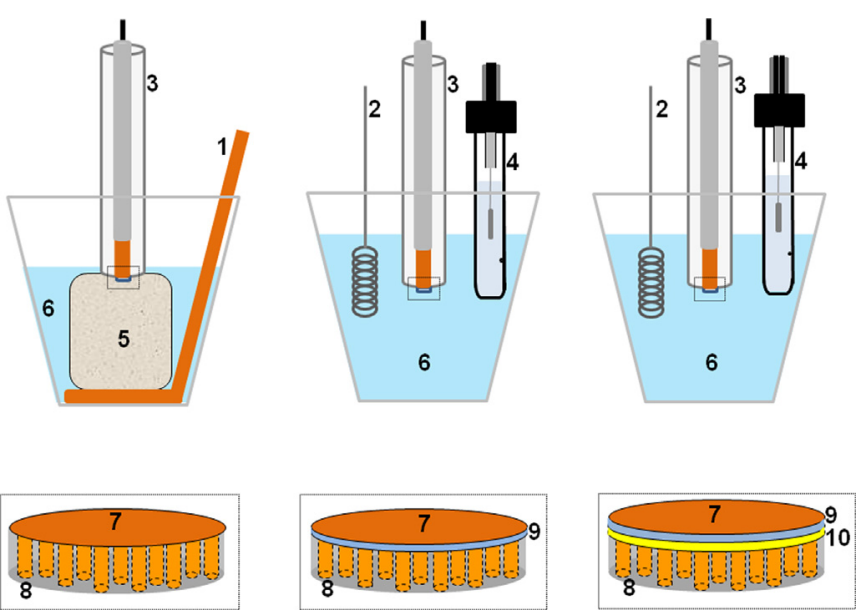

Fig. 1. Scheme illustrating the three template deposition methods which differ for the way used to contact the PC membrane (8) to the flat disk Cu electrode (7). From left to right: (A) adhesion by the pressure furnished by the melamine foam (5); (B) adhesion by using a Nafion interlayer (9) as polyelectrolytic glue; (C) as (B), but using a PC membrane pre-sputtered with the gold interlayer (10). Other components: (1) $\mathrm{Cu}$ counter electrode, (2) Pt counter electrode, (3) working electrode, (4) $\mathrm{Ag} / \mathrm{AgCl}$ $\mathrm{KCl}$ sat reference electrode, (6) $0.4 \mathrm{M} \mathrm{CuSO}_{4}, 0.01 \mathrm{M} \mathrm{H}_{2} \mathrm{SO}_{4}$ solution.

Preliminary tests in $0.4 \mathrm{M} \mathrm{CuSO}_{4}, 10^{-2} \mathrm{M} \mathrm{H}_{2} \mathrm{SO}_{4}$, indicated that performing the deposition for $120 \mathrm{~s}$ at $-0.250 \mathrm{~V}$ for method (A) and $-0.150 \mathrm{~V}$ for methods (B) and (C), was effective in filling almost completely the pores with metallic copper; longer deposition time caused the further growth of the deposit outside the pores, as confirmed by SEM observations and by the sharp increase in deposition current observed with durations > 120 s [34]. Using deposition time in the order of 60 s or lower, rather short fibers were obtained.

\subsection{Characterization of CUWNEEs}

Fig. 2A 2B, 2C report the SEM images of the surfaces of CuWNEEs obtained with method (A), (B), and (C), respectively, after removal of the template; for comparison, the surface of a flat $\mathrm{CuE}$ is shown in Fig. 2D. All three the CuWNEEs result coated by homogeneously distributed ensembles of copper nanowires, all with comparable length and diameter and whose elemental composition (i.e., $\mathrm{Cu}$ ) was confirmed by EDS data (not shown). Inspection of the SEM images indicates that the wires diameter is $400 \pm 25 \mathrm{~nm}$ with a spatial density $1 \times 10^{8}$ wires $\mathrm{cm}^{-2}$. Note that from the above SEM images it is difficult to estimate accurately the length of the nanowires, but an approximate evaluation suggests that their length is around $10 \mu \mathrm{m}$. All these values are in agreement with the characteristics expected on the basis of the geometrical features of template PC membrane. These SEM data indicated that no significant difference is observed in the morphology of the CuWNEEs as a function of the different preparation methods.

The growth of $\mathrm{Cu}$ nanowires on the electrode surface is expected to increase the active area $\left(A_{a c t}\right)$ of the sensor, reflecting in the increase of the double layer charging current $\left(I_{C}\right)$. With the aim of evaluating such an increase in $A_{a c t}$, cyclic voltammograms (CVs) at $\mathrm{CuE}$, and CuWNEE (prepared according to method $\mathrm{C}$ ) were recorded at different scan rates in pure supporting electrolyte. From these blank CVs, $I_{C}$ values were calculated as the half difference between
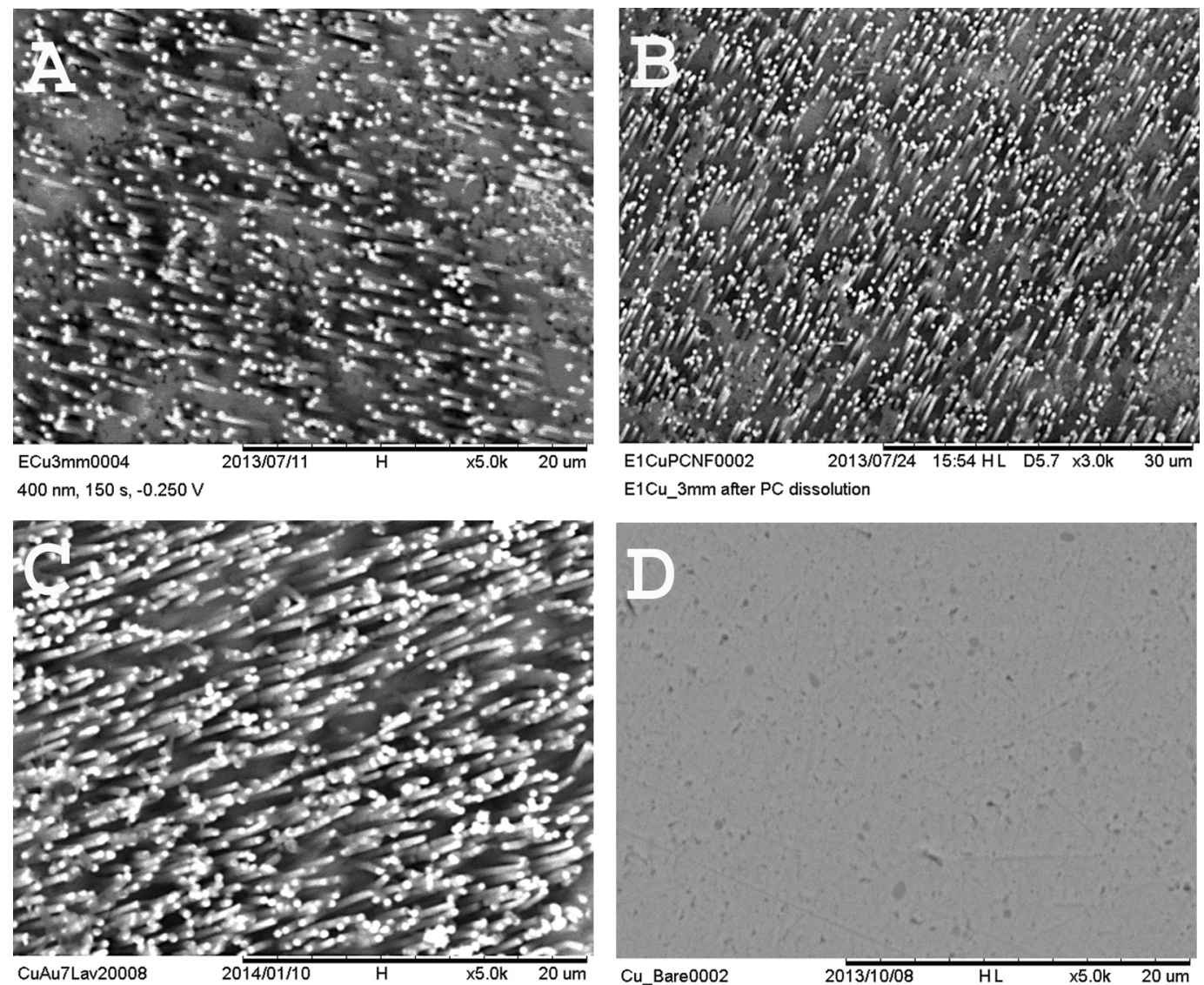

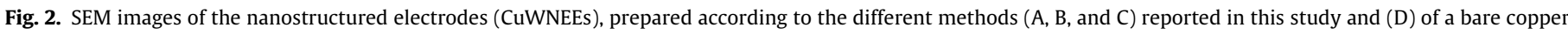
electrode (CuE). 


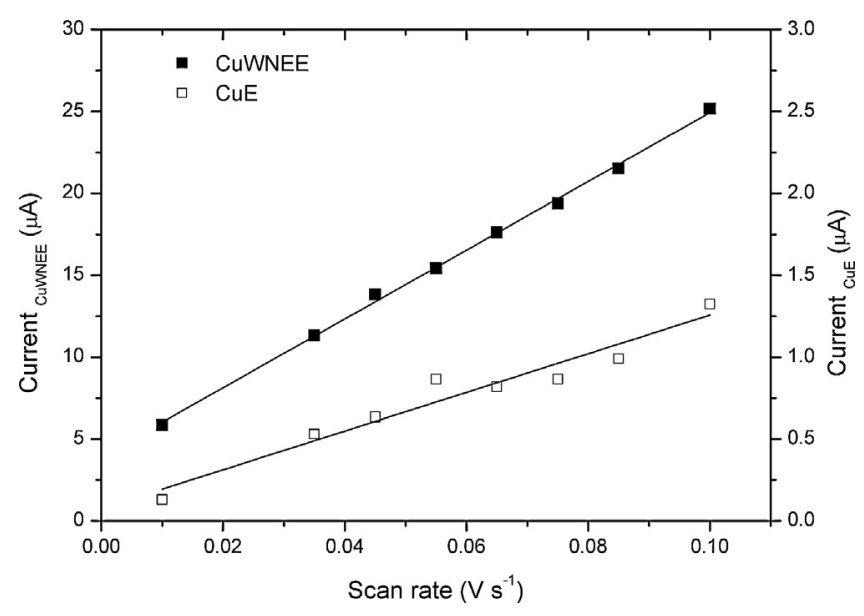

Fig. 3. Dependence of the capacitive current $\left(I_{C}\right)$ on the scan rate for a CuE (right Y-axis $\square$ ) and a CuWNEE (left Y-axis $\mathbf{\square}$ )

the anodic and cathodic current [35] measured at $0.3 \mathrm{~V}$. From the slopes of the linear plots shown in Fig. 3 by using Eq. (1):

$A_{a c t}=\frac{C_{d l} v}{I_{c}}$,
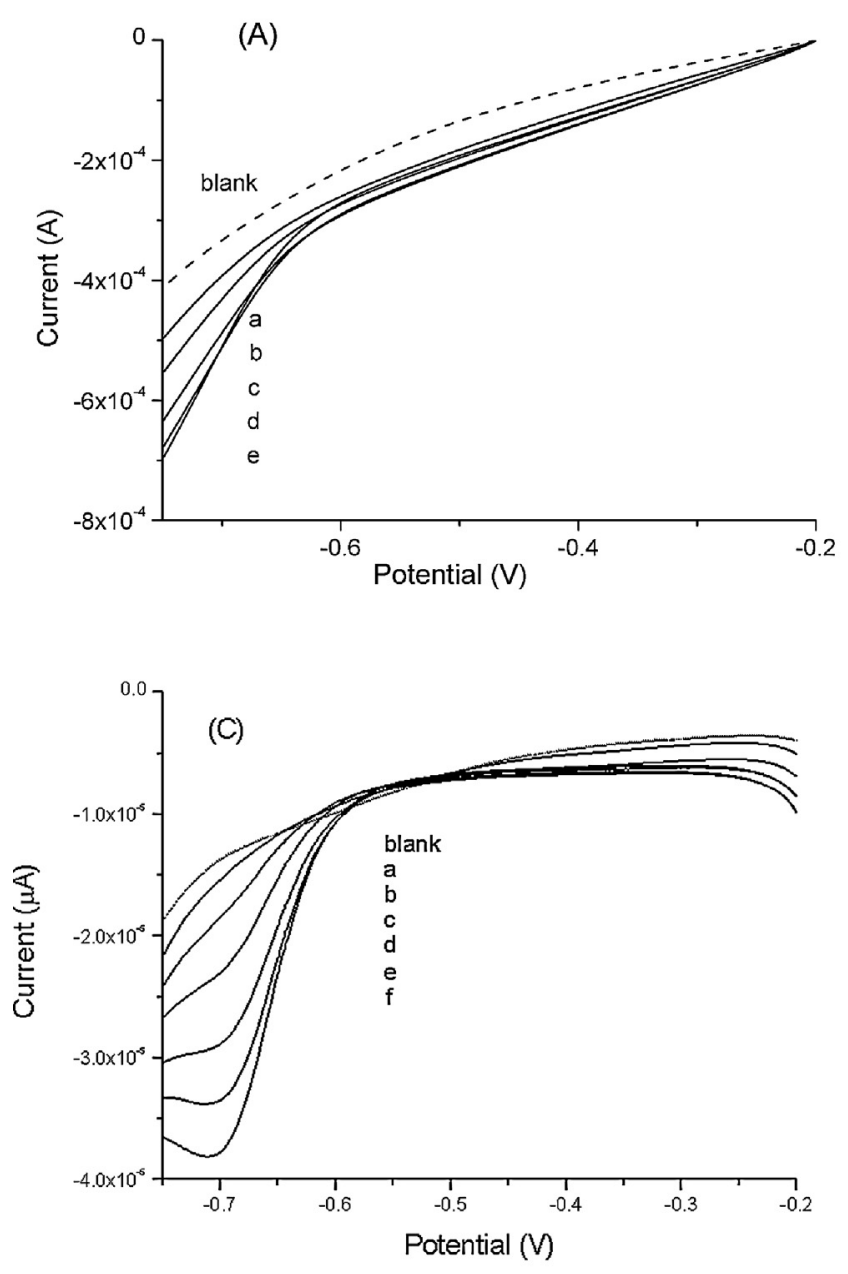

where $v\left(\mathrm{~V} \mathrm{~s}^{-1}\right)$ is the scan rate and $C_{d l}\left(\mu \mathrm{Fcm}^{-2}\right)$ is the double layer capacitance. The plots in Fig. 3 indicate that CuWNEEs present an active area approximately 18-times higher than the CuE. From the slope relevant to the $\mathrm{CuE}$ (namely, $11.8 \mu \mathrm{As} \mathrm{V}^{-1}$ ), knowing that the geometric area of the flat electrode is $0.071 \mathrm{~cm}^{2}$, a $C_{d l}$ value of $166 \mu \mathrm{F} \mathrm{cm}^{-2}$ was calculated. From this $C_{d l}$ value, the active area calculated for CuWNEE was $1.26 \mathrm{~cm}^{2}$, which corresponds to the area expected for an array of nanowires (diameter $400 \mathrm{~nm}$, length $10 \mu \mathrm{m}$ ) distributed in a surface of $0.071 \mathrm{~cm}^{2}$ with a density of $1 \times 10^{8}$ nanowires $\mathrm{cm}^{-2}$. These double layer charging current values agree with morphologic data estimated by SEM analyses.

\subsection{Electrochemical Reduction of Nitrate at CuWNEEs}

Fig. 4 compares the linear sweep voltammograms (LSVs) recorded in solutions containing increasing nitrate concentrations, recorded with a $\mathrm{CuE} \mathrm{(Fig.} 4 \mathrm{~A}$ ) or a CuWNEE (Fig. 4B); note that the CuWNEE used for recording the data shown in Fig. 4B was prepared by method (C). Preliminary CV tests showed that, in the return anodic scan no peak was observed, confirming the irreversibility of the electrochemical nitrate reduction [35]. Therefore, to the aim of the present study, the use of the simpler LSV technique was preferred with respect to CV. LSV patterns recorded at the nanostructured electrode are characterized by a cathodic peak at approximately $-0.680 \mathrm{~V}$ whose current scales linearly with the
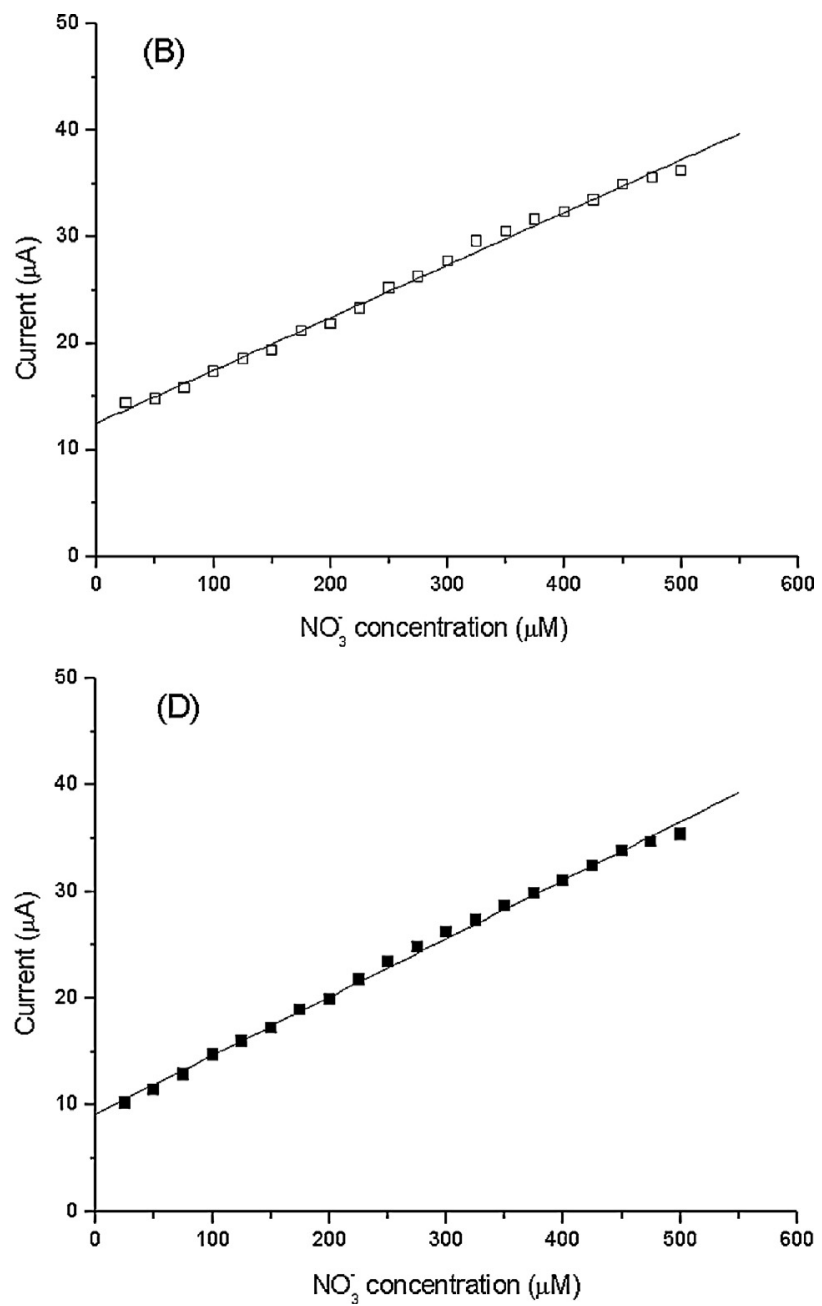

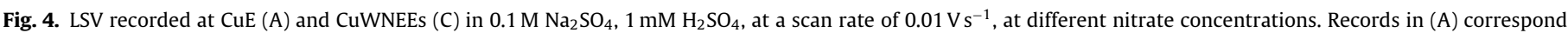

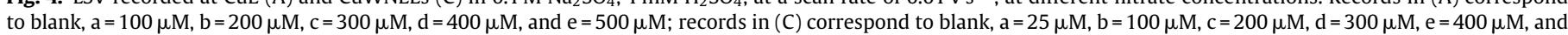
$\mathrm{f}=500 \mu \mathrm{M}$. (B) and (D) calibration plots with the CuE and CuWNEE, respectively. 
Table 1

Parameters relevant to calibration plots obtained by LSVs recorded with CuEs and CuWNEEs, in nitrate solutions.

\begin{tabular}{|c|c|c|c|c|c|c|}
\hline Method & $\begin{array}{l}\text { Blank signal } \\
\text { (intercept) } \mu \mathrm{A}\end{array}$ & $\begin{array}{l}\text { Sensitivity (slope) } \\
\mu \mathrm{A} / \mu \mathrm{M}\end{array}$ & $\begin{array}{l}\text { Blank standard } \\
\text { deviation }(\mu \mathrm{A})\end{array}$ & $\operatorname{LOD}(\mu \mathrm{M})$ & $\begin{array}{l}\text { Range of linearity } \\
(\mu \mathrm{M})\end{array}$ & $R^{2}$ \\
\hline (A)-(CuWNEEs) & 0.48 & 0.05 & 0.05 & 3.0 & $10-400$ & 0.998 \\
\hline (B)-(CuWNEEs) & 0.39 & 0.07 & 0.04 & 1.7 & $5-350$ & 0.998 \\
\hline (C)-(CuWNEEs) & 0.26 & 0.06 & 0.05 & 2.5 & $8-500$ & 0.998 \\
\hline Bare $(\mathrm{CuE})$ & -1.50 & 0.03 & 1.20 & 120.0 & $300-550$ & 0.962 \\
\hline
\end{tabular}

nitrate concentration (see Fig. 4, inset) and with the square root of the scan rate (not shown); for instance, with $100 \mu \mathrm{M}$ nitrate the slope of the Ip vs $\mathrm{v}^{1 / 2}$ plot is $156 \mu \mathrm{As}^{1 / 2} \mathrm{~V}^{-1 / 2}$, coefficient of determination $\mathrm{R}^{2}=0.999$. This behavior agrees with a diffusion controlled process. Increasing nitrate concentration reflects in an increase of overall cathodic current also at the flat $\mathrm{CuE}$, however, in this case no peak is clearly detected; moreover, the current increase at $-0.680 \mathrm{~V}$ is not fully monotone. Note that some LSV patterns recorded at different solution concentration of $\mathrm{NO}_{3}{ }^{-}$, even overlap. These evidences indicate that, even if the CuE can be eventually used to detect nitrate, much more reliable and analytically useful voltammetric signals are obtained with the CuWNEE. Voltammetric patterns comparable to those in Fig. 4B were obtained also with the CuWNEEs prepared with methods (A) and (B); data relevant to the calibration plots obtained with these electrodes are listed in Table 1. Note that no background current subtraction was performed, so that the intercepts on the Y-axis correspond to the blanks signal. Background noise $\left(s_{b}\right)$ was evaluated from repeated measurements $(n=5)$ of the blank current at $-0.680 \mathrm{~V}$; the fifth column in Table 1 reports the limit of detection (LOD) calculated as 3 times $s_{b} / m$, where $m$ is the sensitivity (slope of the calibration plot). For all the CuWNEEs prepared with the different method, good analytical performances were observed. Data in Table 1 indicate significant improved analytical performance of the CuWNEE sensors with respect to traditional CuE. In particular, a 2 fold increase in the sensitivity is observed, to which an even more significant lowering of the background noise is associated (around 30 times). These reflect in a dramatic lowering of calculated LOD values which are in the 1.7-3.0 $\mu \mathrm{M}$ range for the CuWNEEs. Indeed, as inferred by data in Fig. $4 \mathrm{C}$ and D, a signal clearly distinguishable from the blank is detected in the $10-25 \mu \mathrm{M}$ range. It is worth to note that the increase in sensitivity of the CuWNEEs with respect to the $\mathrm{CuE}$ is of the order of a-2.2 factor, while the increase in active area, estimated both by the capacitive currents and geometrical calculation (see above), was almost one order of magnitude larger. This result is explained by the fact that CuWNEEs (like all NEEs prepared by commercially available track-etched polycarbonate membranes) operate under total overlap diffusion regime [3].

As discussed in a previous study devoted specifically to this issue, under such diffusion conditions, not all the active area of the nanowires in a 3D ensemble is effective in increasing the faradaic current so that only a fraction of the $A_{a c t}$ increase is finally exploited, this fraction depending on the kinetics of the heterogeneous electron transfer process [28]. In the present case, the (moderate) increase in sensitivity combined with a significantly lowering of the background noise is anyhow effective in achieving a significant decrease in detection limits. Note that LOD values here obtained with CuWNEEs are among the lowest reported in the literature for nitrate electroanalyses, where previous values were in the $6-12.5 \mu \mathrm{M}$ range [10,12,36,37], with the only exception of Hazefi et al. [38], who reported a LOD of $0.59 \mu \mathrm{M}$, however, operating under hydrodynamic flow conditions.

On the other hand, while examining the repeatability and lifetime of the different nanostructured sensors compared in this study, it was observed that the surface of the CuWNEEs obtained by method (A) and (B) tends to deteriorate with use, while arrays obtained by method (C) are more robust and furnish more reproducible result. For the better reproducibility and robustness, in the following, we focus on the performances of CuWNEEs prepared with method (C).

\subsection{Effect of Chloride and Nitrite}

It is documented in the literature that chloride can influence the reduction of nitrate at copper electrodes [10,22,24,25,27]. Fig. 5 shows the LSV recorded at a CuWNEE in $1 \mathrm{mM}$ chloride at increasing nitrate concentration. The pattern displays a complex behavior with a first broad peak (I) at approximately $-0.350 \mathrm{~V}$ which decreases with increasing nitrate concentration and a second peak (II), at about $-0.600 \mathrm{~V}$, which increases with nitrate. Since in this case the baseline of peak (II) changes with the nitrate concentration, its peak current was evaluated by subtracting the decay
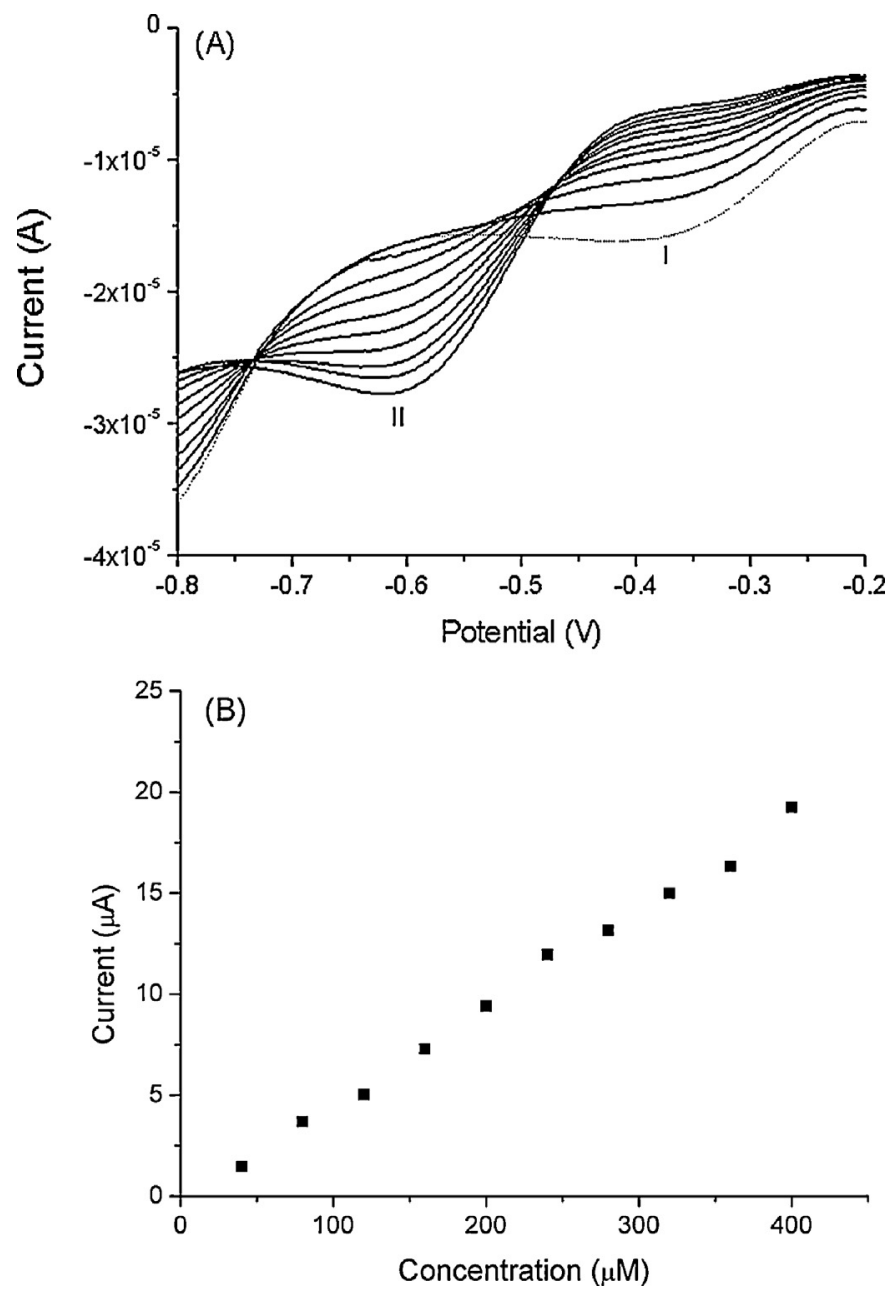

Fig. 5. (A) LSV recorded with a CuWNEE in $1 \mathrm{mM} \mathrm{HCl}$, in blank solution (dashed line) and at increasing concentration of nitrate, from 40 to $400 \mu \mathrm{M}$; peak II increases with nitrate concentration. (B) Calibration plot relevant to peak (II), after baseline subtraction (see text). Other parameters as in Fig. 4. 

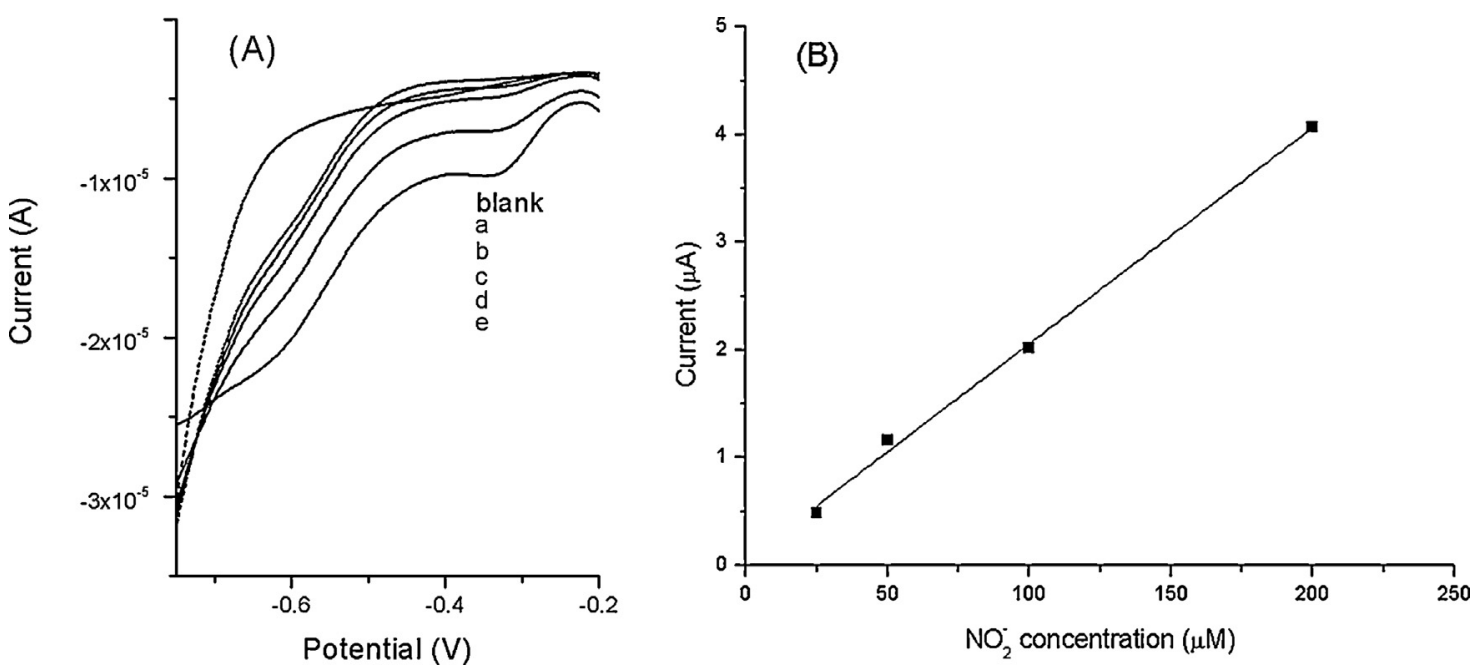

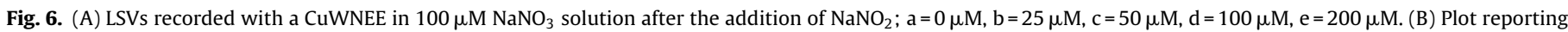
the peak current measured at $-0.340 \mathrm{~V}$ vs $\mathrm{Ag} / \mathrm{AgCl}$ (after background subtraction) as a function of $\mathrm{NaNO}_{2}$ concentration.

current of peak (I) as baseline. Data in the inset in Fig. 5 indicate a linear increase of the current of peak (II) with nitrate concentration so confirming the attribution of this peak to nitrate reduction. On the other hand, the first broad peak (I), present even in the absence of nitrate, appears related to interaction of $\mathrm{Cu}(\mathrm{I})$ with chloride [39]. In the presence of chloride, the oxidation of metallic copper is anticipated by the formation of the $\mathrm{CuCl}_{2}{ }^{-}$complex [40-42], which can indeed be formed in the presence of chloride already at a potential of $-0.2 \mathrm{~V}$. The reduction process at peak (I) can be therefore attributed to the re-reduction of the $\mathrm{Cu}(\mathrm{I})$ complex to copper metal. The reason why this peak decreases with $\mathrm{NO}_{3}{ }^{-}$concentration can be explained taking into account that nitrate reduction involves adsorption of $\mathrm{NO}_{3}{ }^{-}$ions on the copper surface [10] with consequent adsorption competition between $\mathrm{Cl}^{-}$and $\mathrm{NO}_{3}{ }^{-}$.

However, to the aims of the present study, even if some mechanistic complication affects the detection process, the above results indicate that CuWNEEs can be used to determine nitrate also in chloride-containing media, with the caution of measuring the nitrate reduction peak current (peak (II) in Fig. 5A) using the proper baseline signal, that is the decay current of peak (I).

It is known from the literature [22,25], that copper electrodes can respond also to nitrite. In order to check such a possibility we examined the effect on the LSV patterns of adding increasing nitrite concentration (from 0 to $200 \mu \mathrm{M}$ ) to a sample containing $100 \mu \mathrm{M}$ nitrate. As shown by data in Fig. 6A, the addition of $\mathrm{NO}_{2}{ }^{-}$ reflects in the appearance of a new cathodic peak at $-0.340 \mathrm{~V}$ whose current increases linearly with nitrite concentration (see Fig. 6B). This peak potential value agrees with the one reported by Compton et al. for nitrite at macroporous electrodes [25]. Note that the nitrite reduction peak at CuWNEEs is well separated from the nitrate peak causing only an increase of the baseline at the potential where nitrate reduction occurs. It can be noted that the sensitivity (slope) of the $\mathrm{NO}_{2}{ }^{-}$calibration plot is $0.018 \mu \mathrm{A} / \mu \mathrm{M}$, that is more than 3 times smaller than the sensitivity for $\mathrm{NO}_{3}{ }^{-}$. These results indicate that the presence of $\mathrm{NO}_{2}{ }^{-}$is not a major problem since both anions can be eventually detected and quantified independently from the same voltammetric scan, with higher sensitivity for nitrate.

The possibility to apply CuWNEEs to drinking water was checked determining nitrate in samples of bottled mineral water. The applicability of the method resulted in successful furnishing data which agreed within $\pm 4.5 \%$ with the data obtained by ion-chromatography on the same samples. Further studies concerning application of CuWNEEs to other kind of real samples are in progress.

\section{Conclusions}

Membrane template electrodeposition of copper allowed us to prepare ensembles of CuWNEEs with highly controlled morphology, which demonstrated efficient sensing performances with respect to nitrate determination at concentration levels as low as few $\mu \mathrm{M}$. The comparison between different template deposition procedures indicated that the pre-sputtering of a thin layer of gold one face of the template helps in improving the robustness and time length of use of the ensemble. On the other hand, in cases when a sputtering apparatus is not available, it is possible to prepare CUWNEEs, characterized by still satisfactory analytical performances, by using simpler procedures, such as the procedures named $A$ and $B$ in this work.

If, on one side, the sensing performances of the CuWNEEs are fully satisfactory for analytical goals and these arrayed sensors can possibly find practical application, the full clarification of all the mechanistic details behind the electrochemical reduction of nitrate at CuWNEEs will require more finalized studies. In particular, further research efforts are required to clarify the role of the ensemble morphology and heterogeneous electron transfer kinetics on the sensitivity enhancement of the CuWNEE sensor as well as the competing role that chloride and nitrite can play on the electrochemical reduction of nitrate.

\section{Acknowledgement}

The authors wish to thank Dr. Monica Favaro, Dr. Arianna Gambirasi and Dr. Antonio Aguiari from CNR-IENI (Padua, Italy) for useful discussion and technical suggestions and Dr. Sabrina Fabris for the ion-chromatographic analyses. Financial support by MIUR (Rome), project PRIN 2010AXENJ8 is gratefully acknowledged.

\section{References}

[1] S.P. Mucelli, M. Zamuner, M. Tormen, G. Stanta, P. Ugo, Nanoelectrode ensembles as recognition platform for electrochemical immunosensors, Biosens. Bioelectron. 23 (2008) 1900-1903.

[2] M. Silvestrini, L. Fruk, P. Ugo, Functionalized ensembles of nanoelectrodes as affinity biosensors for DNA hybridization detection, Biosens. Bioelectron. 40 (2013) 265-270.

[3] V.P. Menon, C.R. Martin, Fabrication and evaluation of nanoelectrode ensembles, Anal. Chem. 67 (1995) 1920-1928.

[4] C.G. Zoski, N. Yang, Addressable nanoelectrode membrane arrays: fabrication and steady-state behavior, Anal. Chem. 79 (2007) 1474-1484. 
[5] R. Gasparac, B.J. Taft, M.A. Lapierre-Devlin, A.D. Lazareck, J.M. Xu, S.O. Kelley, Ultrasensitive electrocatalytic DNA detection at two- and three-dimensional nanoelectrodes, J. Am. Chem. Soc. 126 (2004) 12270-12271.

[6] A. Mardegan, S. Dal Borgo, P. Scopece, L.M. Moretto, S.B. Hočevar, P. Ugo Bismuth modified gold nanoelectrode ensemble for stripping voltammetric determination of lead, Electrochem. Commun. 24 (2012) 28-31.

[7] M. Ongaro, P. Ugo, Bioelectroanalysis with nanoelectrode ensembles and array, Anal. Bioanal. Chem. 405 (2013) 3715-3729.

[8] A. Mardegan, P. Scopece, F. Lamberti, M. Meneghetti, L.M. Moretto, P. Ugo, Electroanalysis of trace inorganic arsenic with gold nanoelectrode ensembles, Electroanalysis 24 (2012) 798-806.

[9] A. Gambirasi, S. Cattarin, M. Musiani, L. Vázquez-Gómez, E. Verlato, Direct electrodeposition of metal nanowires on electrode surface, Electrochim. Acta. 56 (2011) 8582-8588.

[10] G.E. Dima, A.C.A. De Vooys, M.T.M. Koper, Electrocatalytic reduction of nitrate at low concentration on coinage and transition-metal electrodes in acid solutions, J. Electroanal. Chem. 554-555 (2003) 15-23.

[11] American Public Health Association (APHA), Standard Methods for the Examination of Water and Wastewater, 18th Ed., American Public Health Association, Washington, DC, 1992.

[12] M.J. Moorcroft, J. Davis, R.G. Compton, Detection and determination of nitrate and nitrite: a review, Talanta 54 (2001) 785-803.

[13] P. Ugo, L.M. Moretto, B. Ballarin, Nitrate detection at Nafion-modified electrodes incorporating ytterbium and uranyl electrocatalysts, Electroanalysis 7 (1995) $129-131$.

[14] C.M.N. Azevedo, K. Araki, L. Angnes, H.E. Toma, Electrostatically assembled films for improving the properties of tetraruthenated porfirin modified electrodes, Electroanalysis 10 (1998) 467.

[15] Z. Liu, X. Xi, S. Dong, E. Wang, Liquid chromatography amperometric detection of nitrite using a polypyrrole modified glassy carbon electrode doped with tungstodiphosphate anion, Anal. Chim. Acta 345 (1997) 147-153.

[16] S. Da Silva, D. Shan, S. Cosnier, Improvement of biosensor performances for nitrate determination using a new hydrophilic poly (pyrrole-viologen) film, Sens. Actuat. B Chem. 103 (2004) 397-402.

[17] S.A. Glazier, E.R. Campbell, W.H. Campbell, Construction and characterization of nitrate reductase-based amperometric electrode and nitrate assay of fertilizers and drinking water, Anal. Chem. 70 (1998) 1511-1515.

[18] L.M. Moretto, P. Ugo, M. Zanata, P. Guerriero, C.R. Martin, Nitrate biosensor based on the ultrathin-film composite membrane concept, Anal. Chem. 70 (1998) 2163-2166.

[19] D. Pletcher,Z. Poorabedi, The reduction of nitrate at a copper cathode in aqueous acid, Electrochim. Acta 24 (1979) 1253-1256.

[20] M. Shibata, K. Yoshida, N. Furuya, Electrochemical synthesis of urea on reduction of carbon-dioxine with nitrate and nitrite ions using $\mathrm{Cu}$-loaded gasdiffusion electrode, J. Electroanal. Chem. 387 (1995) 143-145.

[21] M. Shibata, K. Yoshida, N. Furuya, Electrochemical synthesis of urea at gasdiffusion electrodes-IV. Simultaneous reduction of carbon dioxide and nitrate ions with various metal catalysts, J. Electrochem. Soc. 145 (1998) 2348-2353.

[22] N.G. Carpenter, D. Pletcher, Amperometric method for the determination of nitrate in water, Anal. Chim. Acta 317 (1995) 287-293.

[23] S. Cattarin, Electrochemical reduction of nitrogen oxyanions in 1-M sodiumhydroxide solutions at silver, copper and CuINSE2 electrodes, J. Appl. Electrochem. 22 (1992) 1077-1081.

[24] I.S. da Silva, W.R. de Araujo, T.R.L.C. Paixao, L. Angnes, Direct nitrate sensing in water using an array of copper-microelectrodes from flat flexible cables, Sens. Actuat. B Chem. 188 (2013) 94-98.

[25] J. Davis, M.J. Moorcroft, S.J. Wilkins, R.G.Compton, M.F. Cardosi, Electrochemical detection of nitrate and nitrite at a copper modified electrode, Analyst 125 (2000) 737-742.

[26] D. Reyter, M. Odziemkowski, D. Belanger, L. Roue, Electrochemically activated copper electrodes, J. Electrochem. Soc. 154 (2007) K36-K44.

[27] A.S. Lima, M.O. Salles, T.L. Ferreira, T.R.L.C. Paixao, M. Bertotti, Scanning electrochemical microscopy investigation of nitrate reduction at activated copper cathodes in acidic medium, Electrochim. Acta 78 (2012) 446-451.

[28] M. De Leo, A. Kuhn, P. Ugo, 3D-Ensembles of gold nanowires: preparation, characterization and electroanalytical peculiarities, Electroanalysis 19 (2007) 227-236.

[29] M.C. Henstridge, E.J.F. Dickinson, M. Aslanoglu, C. Batchelor-McAuley, R.G. Compton, Voltammetric selectivity conferred by the modification of electrodes using conductive porous layers or films: the oxidation of dopamine on glassy carbon electrodes modified with multiwalled carbon nanotubes, Sens. Actuat. B 145 (2010) 417-427.

[30] I. Streeter, G.G. Wildgoose, L.D. Shao, R.G. Compton, Cyclic voltammetry on electrode surfaces covered with porous layers: an analysis of electron transfer kinetics at single-walled carbon nanotube modified electrodes, Sens. Actuat. B 133 (2008) 462-466.

[31] B.R. Kozub, N.V. Rees, R.G. Compton, Electrochemical determination of nitrite at a bare glassy carbon electrode; why chemical modified electrodes? Sens. Actuat. B 143 (2010) 539-546.
[32] P. Ugo, L.M. Moretto, Template deposition of metals, in: C. Zosky (Ed.), Handbook of Electrochemistry, Elsevier, Amsterdam, 2007, pp. 678-709.

[33] M. De Leo, F.C. Pereira, L.M. Moretto, P. Scopece, S. Polizzi, P. Ugo, Towards a better understanding of gold electroless deposition in track-etched templates, Chem. Mater. 19 (2007) 5955-5964.

[34] M. De Leo, Nanoelectrode ensembles for electrochemical sensing purposes, $\mathrm{PhD}$ Thesis, University Ca' Foscari, Venice, 2006.

[35] A.J. Bard, L.R. Faulkner, Electrochemical Methods: Fundamentals and Applications, Wiley, New York, 2001.

[36] S.E. Bae, K.L. Stewart, A.A. Gerwirth, Nitrate adsorption and reduction on $\mathrm{Cu}(100)$ in acidic solution, J. Am. Chem. Soc. 129 (2007) 10171-10180.

[37] A.S. Adekunle, B.B. Mamba, B.O. Agboola, K.I. Ozoemena, Electrodeposition of copper nano-clusters at a platinum microelectrode for trace nitrate determination, Int. J. Electrochem. Sci. 6 (2011) 4388-4403.

[38] B. Hafezi, M.R. Majidi, A sensitive and fast electrochemical sensor based on copper nanostructures for nitrate determination in foodstuffs and mineral waters, Anal. Methods 5 (2013) 3552-3556.

[39] P. Ugo, L.M. Moretto, G.A. Mazzocchin, Ion-exchange voltammetry of copper ions in chloride media at glassy carbon electrodes modified with polycationc ionomers, Anal. Chim. Acta 273 (1993) 229-236.

[40] P. Dawei, L. Wenjing, Z. Haiyun, Z. Li, J.M. Zhuang, Voltammetric determination of nitrate in water samples at copper modified bismuth bulk electrode, Int. J. Environ. Anal. Chem. 93 (2013) 935-945.

[41] G. Gunawardena, G. Hills, I. Montenegro, Electrochemical nucleation: Part IV Electrodeposition of copper onto vitreous carbon, J. Electroanal. Chem. Interf. Electrochem. 184 (1985) 357-369.

[42] J. Crousier, I. Bimaghra, Electrodeposition of copper from sulfate and chloride solutions, Electrochim. Acta 34 (1989) 1205-1211.

\section{Biographies}

Angela Maria Stortini (Ph.D.) is researcher at the University Ca' Foscari of Venice since 2011. She graduated in Biological Sciences at the University of Florence (1990) where she earned her PhD in Environmental Sciences (1995). She collaborated with research institution such as Inter-University Centre of Marine Biology (Livorno), the Institute for the Dynamics of Environmental Processes (IDPA-CNR, Venice) and took part to several research expeditions of the National Program of Antarctic Research (PNRA), at Terra Nova Bay (Antarctica). Her main research interest is on environmetal analysis and monitoring.

Ligia Maria Moretto (Ph.D.) graduated in Chemical engineering at the Federal University of Rio Grande do Sul, Brazil, received her PhD in 1994 from the University Ca' Foscari of Venice. Since 1996 she is researcher at the University Ca' Foscari of Venice, in the Laboratory of Electrochemical Sensors, working in the development of electrochemical sensor and biosensors based on modified electrodes, on gold arrays and ensembles of nanoelectrodes, with particular attention to environmental applications. Dr. Moretto collaborates as invited professor and invited researcher with several institutions in Brazil, France, Argentina, Canada and USA.

Andrea Mardegan (Ph.D.) earned the Bachelor and Master Degree in Industrial Chemistry at the University Ca' Foscari of Venice. During the PhD, Dr. Mardegan developed advanced materials for the electroanalysis of inorganic pollutants. He worked (2010-2013) at CIVEN (Venezia) and at Veneto Nanotech (from June 2013). He started two international collaborations thanks to internships at the Slovenian Chemical Institute (Ljubljana) and at the University of California (Irvine).

Michael Ongaro (Ph.D.) is a Post-doctoral researcher at the University Ca'Foscari of Venice. He received his Bachelor degree and his Master degree in Chemistry from the University of Milan (Italy). He completed his Ph.D. in 2013 at the University Ca'Foscari of Venice (Italy) under the supervision of Prof. Paolo Ugo. His research activity focuses on the synthesis and characterization of nanomaterials for energy harvesting and electrochemical sensing applications. More recently his research interest extended to the preparation of hybrid materials by bipolar electrochemistry.

Paolo Ugo (Full Professor) earned his doctor degree in Industrial Chemistry at the University of Venice (Italy) in 1980. He worked as researcher at first for the pharmaceutical company Zambon Farmaceutici and then for the University of Venice, where he was appointed Associate Professor of Analytical Chemistry in 1992 and Full Professor in 2006. In the late 1980s he has been working at Caltech (Pasadena, USA) as Visiting Associate in the group of Prof. Fred C. Anson. He collaborated and is collaborating with several resarch institutions in France, USA, Austria and UK. His research activity dealt with electrochemistry in nonaqueous solvents, polymer coated electrodes, ion-exchange voltammetry arrays of nanoelectrodes and nanoelectrochemistry, electrochemical sensors and biosensors. 